\title{
Status of simulation in health care education: an international survey
}

This article was published in the following Dove Press journal:

Advances in Medical Education and Practice

28 November 2014

Number of times this article has been viewed

\section{Karim Qayumi' \\ George Pachev ${ }^{2}$ \\ Bin Zheng ${ }^{3}$ \\ Amitai Ziv ${ }^{4}$ \\ Valentyna Koval' \\ Sadia Badiei ${ }^{5}$ \\ Adam Cheng 6}

'Center of Excellence for Simulation Education and Innovation,

Department of Surgery, ${ }^{2}$ Faculty of Pharmaceutical Sciences, University of British Columbia, Vancouver, BC, Canada; ${ }^{3}$ Surgical Simulation Research Laboratory, Department of Surgery, Faculty of Medicine and Dentistry, University of Alberta, Edmonton, $A B$, Canada; ${ }^{4}$ srael Center for Medical Simulation, Chaim Sheba Medical Center and Sackler Medical School, Tel Aviv University, Tel Aviv, Israel; ${ }^{5}$ Centre of Excellence for Simulation Education and Innovation, University of British Columbia, Vancouver, BC, Canada; ${ }^{6} \mathrm{KidSIM}$-ASPIRE Simulation Research Program, Alberta Children's Hospital, University of Calgary, Calgary, AB, Canada
Correspondence: Karim Qayumi Centre of Excellence for Simulation Education and Innovation, Department of Surgery, University of British Columbia, Room 3602, 910 West I0th Avenue, Vancouver, BC, V5Z 4E3, Canada

Tel +l 6048754499

Email qayumi@mail.ubc.ca
Abstract: Simulation is rapidly penetrating the terrain of health care education and has gained growing acceptance as an educational method and patient safety tool. Despite this, the state of simulation in health care education has not yet been evaluated on a global scale. In this project, we studied the global status of simulation in health care education by determining the degree of financial support, infrastructure, manpower, information technology capabilities, engagement of groups of learners, and research and scholarly activities, as well as the barriers, strengths, opportunities for growth, and other aspects of simulation in health care education. We utilized a two-stage process, including an online survey and a site visit that included interviews and debriefings. Forty-two simulation centers worldwide participated in this study, the results of which show that despite enormous interest and enthusiasm in the health care community, use of simulation in health care education is limited to specific areas and is not a budgeted item in many institutions. Absence of a sustainable business model, as well as sufficient financial support in terms of budget, infrastructure, manpower, research, and scholarly activities, slows down the movement of simulation. Specific recommendations are made based on current findings to support simulation in the next developmental stages.

Keywords: simulation, health care education, innovation, medical, simulation center, technology-enabled learning

\section{Introduction}

Simulation-based education is a well-recognized modality that complements traditional methods of education in domains such as the military, aviation, law enforcement, and the judiciary system. ${ }^{1-5}$ In health care education, simulation has become increasingly popular in the past few decades, particularly as a method to improve experiential learning environments, ${ }^{6,7}$ and developing simulation as a health care education tool. ${ }^{8-12}$ Support for improved patient safety is one of the primary motivators behind the promotion of simulation in health care. ${ }^{13-19}$ Recently, a number of health care businesses and government bodies also expressed their interest in the support of simulation programs. ${ }^{20-25}$ As a result of this interest, simulation in health care education is growing exponentially across the globe, with health care institutions, organizations, businesses, governments, and licensing and accreditation bodies accepting simulation as a method of learning. ${ }^{10,26,27}$ Several papers describe the status of simulation in health care education and simulation programs for specific centers/regions, ${ }^{9-12}$ but few studies exist on the status of simulation in health care education from a global perspective.

The main objective of this study was to assess the global status of simulation in health care education. This status is described across several dimensions, with the 
aim of this study to paint a picture of simulation in health care education by:

- Describing the engagement of different learner groups and the degree of use and integration of simulation into their curricula

- Describing the frequency of use of different types of simulators

- Describing the research and academic activities of simulation centers

- Exploring the adequacy of infrastructure and financial support for simulation centers, and describing the perceptions of barriers and strengths for individual simulation centers, as well as opportunities for future growth of simulation in health care education

- Highlighting the opportunities for future growth of simulation in health care on a global level.

\section{Materials and methods}

This survey was conducted between 2011 and 2012, with ethics approval from the University of British Columbia Faculty of Medicine research board. The Center of Excellence for Simulation Education and Innovation sent emails to 50 health care education institutions with simulation centers, following up with telephone calls to collect further data. Selection of the centers was heterogeneous with respect to functionality, size, and accreditation status, and primarily from lists provided by accreditors, including the American College of Surgeons, the Royal College of Physicians and Surgeons of Canada, and the Society for Simulation in Healthcare. Nonaccredited simulation centers included those known to us through prior engagement. The criteria for purposeful selection included: a focus on health care, geographic location, and a minimum of 5 years of practice. We studied only the centers that volunteered to participate in the process of answering our questionnaire and provided the opportunity for site visits.

The survey was hosted online at http:// www.cesei.org. For a complete list of surveyed centers and the local leaders who voluntarily participated in our survey, please see Table 1. A glossary of simulation terms used in a previously published manuscript ${ }^{28}$ was used for this study.

A two-phase data collection process was followed, ie, distribution of survey and site visits/individual and group interviews, including with directors and managers.

\section{Survey}

Survey questions targeted fundamental issues in the day-today life of simulation centers. The first area of focus was the learners. We wanted to understand if centers offered multidisciplinary and/or interprofessional programs, or if programs were directed toward specific groups of learners (eg, undergraduates, postgraduates, physicians, nurses, allied health professionals). The survey also aimed to identify a total number of learners in each group to understand which groups used simulation most frequently.

The next area of interest was simulation equipment and technology. Here we aimed to understand what types of simulation are used most frequently, how many simulators from each type are available in each center, and the number of hours each type of simulator was used for training, from which an Activity Index was calculated (estimated number of hours divided by the reported number of simulators from each type). We believe that the number of simulators used in a simulation environment, as well as the hours of use, may not reflect the true activities of a center. A derivative that describes the relationship between the hours of use and the number of simulators in each center may provide a more accurate reflection of activities. Subsequently this data could be used to provide information to center directors as to the usage of certain types of simulators because that will impact where they place their investments.

Part two of the survey focused on integration of simulation as a method of teaching in undergraduate, graduate, and continuing medical education programs. In each of these programs the percentage of various types of simulation activities was identified on a yearly basis.

The next series of questions further compartmentalized simulation activities into areas of skill/competency, patient safety, communication, interprofessional team training, management, scholarly activities/research, professionalism, and health advocacy. The aim was to identify if simulation activities were performed in these areas, and if curricula and/or programs were developed. CanMEDS roles were integrated in this survey ${ }^{29}$ as this framework has been accepted by many in the international health education community, and allowed us to determine if simulation was used for skill training and other competencies such as professionalism and advocacy. We sought to identify the centers' priorities, assigning a priority score (between 1 and 4), in terms of development of simulation curriculum, where 1 was the lowest priority and 4 the highest.

Part three of the survey gathered information about simulation infrastructure, such as specialized manpower, capacity for research and development, and barriers and opportunities. Additional factors that affect development such as financial capacity, faculty development, space 
Table I Complete list of surveyed simulation centers and local collaborators

\begin{tabular}{|c|c|c|}
\hline Institute & Country & Local collaborators \\
\hline University of Buenos Aires & Argentina & AR Ferreres \\
\hline Sydney Clinical Skills and Simulation Centre & Australia & L Watterson \\
\hline Queensland Health Clinical Skills Development Service & Australia & M Watson \\
\hline Prince of Wales Hospital & Australia & R Endre \\
\hline Epworth HealthCare, Private Hospital Organisation, Melbourne, Victoria & Australia & T Vawser \\
\hline University of Sao Paulo, School of Medicine & Brazil & AS Neto \\
\hline University of Ottawa Skills and Simulation Centre & Canada & K Thomas \\
\hline Northumbria University & Canada & A Platts/S McQueen \\
\hline Alberta Children's Hospital & Canada & A Cheng \\
\hline $\begin{array}{l}\text { Center of Excellence for Simulation Education and Innovation, University } \\
\text { of British Columbia }\end{array}$ & Canada & M Woschee \\
\hline McGill University & Canada & L Crelinsten \\
\hline School of Medicine, Shanghai Jiaotong University & People's Republic of China & G Huang \\
\hline West China Clinical Skills Training Center, Sichuan University & People's Republic of China & Q He \\
\hline Athens University Medical School & Greece & E Georgiou \\
\hline The Hong Kong College of Anaesthesiologists & Hong Kong & YF Chow \\
\hline MSR Israel Center for Medical Simulation & Israel & A Ziv/L MacMillan \\
\hline Jordan University of Science and Technology & Jordan & MT Alwidyan \\
\hline Jordan University of Science and Technology, Medical Faculty & Jordan & FM Khwaileh \\
\hline University of Wongju & Korea & M Han \\
\hline Yonsei University College of Medicine & Korea & HS Chung \\
\hline Universidad Nacional Mayor San Marcos & Peru & PW Pujada \\
\hline Umm Al-Qura University, Saudi Arabia & Saudi & S Bajammal \\
\hline Kind Saud University, College of Medicine & Saudi Arabia & HC Taskiran \\
\hline Center for Medical Simulation, Hospital Universitario Marques de Valdecilla & Spain & I Del Moral \\
\hline Skane University Hospital & Sweden & I lhse \\
\hline University of East Anglia & UK & D Grant \\
\hline SiTEL, MedStar Health & USA & Y Millo \\
\hline University of South Florida Health & USA & JH Armstrong \\
\hline Stanford & USA & J Lau \\
\hline Beth Israel Deaconess Medical Center & USA & D Fobert \\
\hline Mayo Clinic Multidisciplinary Simulation Center & USA & D Eagle/Dr Dunn \\
\hline University of California, Irvine, Surgical Education Center & USA & EM McDougall \\
\hline Providence Hospital and Medical Centers & USA & N Gopinath \\
\hline Center for Virtual Care, University of California, Davis & USA & B Bencken \\
\hline The Institute for Simulation and Interprofessional Studies, University of Washington & USA & B Ross \\
\hline University of California, Davis Vascular Center & USA & D Dawson \\
\hline Baystate Medical Center, Tufts University School of Medicine & USA & N Seymour \\
\hline Marcia and Eugene Applebaum Surgical Learning Center at Beaumont Hospital & USA & C Shanley \\
\hline Northwestern University & USA & C Pugh \\
\hline Louisiana State University School of Medicine & USA & J Paige \\
\hline Cedars-Sinai Center for Minimally Invasive Surgery & USA & S Towfigh \\
\hline University of Texas at Arlington & USA & P Andreatta \\
\hline
\end{tabular}

availability, administration, cultural policies, and other issues are also discussed in this section.

\section{Site visits and face-to-face interviews}

Each surveyed center participated in a subsequent site visit, which lasted one full day and included individual and/or group interviews with the directors, managers, and other senior staff. An interview template was designed to standardize the process and best achieve our objectives, which included the following:
- To confirm and clarify the results of the survey

- To explore simulation space, manpower, and infrastructure related issues

- To identify the common needs, difficulties, and issues surrounding simulation centers and programs

\section{Results}

Fifty institutions around the world were invited to participate (Table 1). Forty-two centers (82\%) representing 16 countries over six continents completed the survey. Of these 
42 centers, 26 are accredited (15 by the American College of Surgeons, nine by the Society for Simulation in Health, and two by the Royal College of Physicians and Surgeons of Canada) and 21 are not accredited (some are accredited by more than one institution). Also, of these 42 centers, 32 are university-based or college-based, eight are hospital-based, and two are community-based. Twenty-six of these centers currently conduct active research (Table 2).

It may be noted that while both the US and Canada require all surgical programs to be associated with a simulation center or have a simulation laboratory, only 19 North American programs participated in the survey. The 19 programs that voluntarily participated (on a first come, first served basis) were considered a healthy sample size in relation to the rest of the world. The surveyors felt that more North American participants would introduce bias to the results.

\section{Learner groups and curricular integration}

Most simulation activities are conducted in the context of postgraduate medical programs, followed by continuing professional development for nurses and undergraduate medical education (Figure 1). Simulation for other learner groups is low.

Two-thirds of responding institutions indicated that simulation is integral to their curricula. Figure 2 indicates that use of simulation (estimated percentage of curriculum activity) tends to decrease with advancement through the program. This decrease coincides with an increase in engagement with patients (the exception to this trend is continuing professional development curricula).

Table 3 summarizes the use of simulation as related to the competency domains of CanMEDS. ${ }^{29}$ The most commonly targeted competencies using simulation-based education were skill acquisition, patient safety, communication, and collaboration. Site visits and discussions revealed large variations in the integration of simulation in curricular activities, both across institutions and among learner groups within an institution. Simulation was a mandatory component in only three of the 42 visited sites. Full integration of simulation (defined by this study as simulation integrated into all established curricula wherever applicable across all years) was found only in one institution.

Leaders from simulation centers were asked to rate their priority in developing simulation-based education programs. Topping the priority list with an average score of 3.9 were team training, communication, and patient safety (emergencies), followed by crisis resource management and intensive care unit skills training (3.8), patient safety in patient transfer, handover and skills training for surgical disciplines (3.7), and maintenance of competency and cardiology skills training (3.6).

\section{Use of different categories of simulators}

As measured by the Activity Index, on-line simulation modules were by far the most used modality of learning. The next three most used types of simulation were task trainers, low fidelity human patient simulation, and high fidelity human patient simulation (Figure 3). Low fidelity human patient simulation, high fidelity human patient simulation, and task trainers were the three types of simulation modalities most commonly available for use (Table 3).

\section{Research and academic productivity}

Twenty-six simulation centers of $42(62 \%)$ reported research activities related to simulation. Thirty-six percent of centers had no research activities. Amongst the 26 research-active centers, 141 abstracts were published, 139 papers were published, and 183 presentations were made. These active centers reported receiving 103 grants from different funding organizations in 2011 (average of four grants per center per year). A closer look into these data revealed that $98 \%$ of all research publications originate from just six major centers,

Table 2 Demographics of simulation centers surveyed

\begin{tabular}{|c|c|c|c|c|c|c|c|c|c|c|c|c|c|}
\hline \multirow[t]{3}{*}{ Region } & \multirow{3}{*}{$\begin{array}{l}\text { Centers } \\
\text { (n) }\end{array}$} & \multicolumn{4}{|c|}{ Number accredited } & \multirow{3}{*}{$\begin{array}{l}\text { Infrastructure } \\
\text { of funds }\end{array}$} & \multirow{3}{*}{$\begin{array}{l}\text { Operating } \\
\text { funds }\end{array}$} & \multirow{2}{*}{\multicolumn{2}{|c|}{ Research }} & \multirow{2}{*}{\multicolumn{2}{|c|}{$\begin{array}{l}\text { Trained } \\
\text { experts } \\
\end{array}$}} & \multicolumn{2}{|l|}{ Location } \\
\hline & & \multirow[t]{2}{*}{$\bar{n}$} & \multirow[t]{2}{*}{ ACS } & \multirow[t]{2}{*}{ RCSPC } & \multirow[t]{2}{*}{ SSH } & & & & & & & \multirow{2}{*}{$\begin{array}{l}\text { Universityl } \\
\text { college }\end{array}$} & \multirow[t]{2}{*}{ Hospital } \\
\hline & & & & & & & & $\mathbf{Y}$ & $\mathbf{N}$ & $\mathbf{Y}$ & $\mathbf{N}$ & & \\
\hline USA & 13 & 4 & 9 & 0 & 5 & Good & Variable & 9 & 4 & 11 & 2 & 12 & $\mathrm{I}$ \\
\hline Canada & 6 & 3 & 0 & 2 & I & Good & Variable & 3 & 3 & 3 & 3 & 3 & 3 \\
\hline Australia & 5 & 3 & 0 & 0 & 2 & Good & Good & 3 & 2 & 4 & 1 & I & 4 \\
\hline Europe & 5 & 2 & 3 & 0 & I & Good & Variable & 4 & I & 5 & 0 & 4 & I \\
\hline South & 3 & 3 & 0 & 0 & 0 & Variable & Variable & 1 & 2 & I & 2 & 3 & 0 \\
\hline \multicolumn{14}{|l|}{ America } \\
\hline Asia & 10 & 7 & 3 & 0 & 0 & Variable & Variable & 6 & 3 & 4 & 5 & 9 & 0 \\
\hline
\end{tabular}

Abbreviations: ACS, American College of Surgeons; RCSPC, Royal College of Physicians and Surgeons of Canada; SSH, Society for Simulation in Healthcare; Y, yes; N, no. 


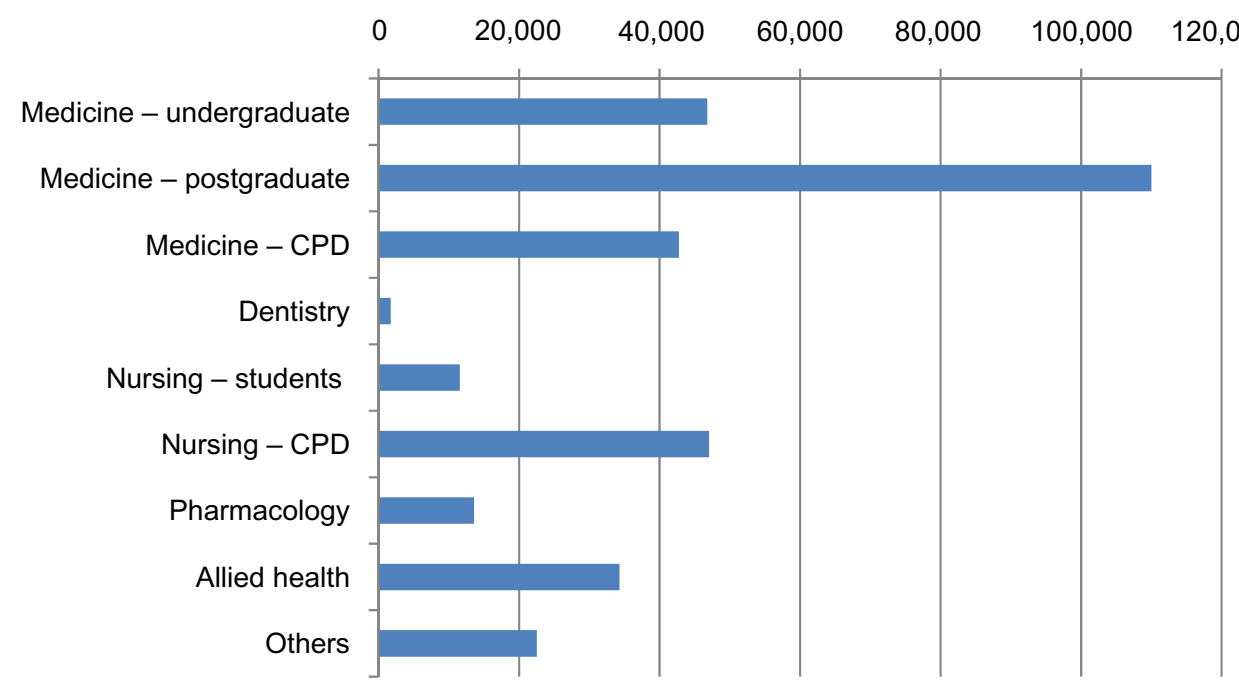

Figure I Number of learners from each group.

Abbreviation: $\mathrm{CPD}$, continuing professional development.

showing a huge discrepancy in research activities between centers. Our study indicates that research on effectiveness of simulation-based education was the most frequently conducted, followed by psychometric evaluation studies on the assessment of tools and technologies, then studies on the satisfaction of educators and learners, and finally, with the lowest percentage of research conducted, were studies on the cost-effectiveness of simulation-based education.

\section{Infrastructure support, strengths, and barriers}

With respect to human resources and infrastructure, 28 simulation centers of 42 (66\%) had full-time simulation instructors. The total number of full-time instructors was 660 .
There were also 521 part-time instructors teaching simulation courses, meaning each center has an average of 24 simulation instructors (amongst the 28 centers who reported having full-time simulation instructors) and eleven part-time instructors.

Each simulation center was asked to identify the main strengths and barriers for their programs (Table 4). The top strengths identified were: dedicated financial support, dedicated simulation technicians, and support from institutional leaders. Ironically, the top two barriers listed were the need for more financial support and the need for a dedicated simulation technician. Similarly, instructor training was highly rated as both a strength and a barrier. These results suggest a huge disparity in resources and infrastructure support in

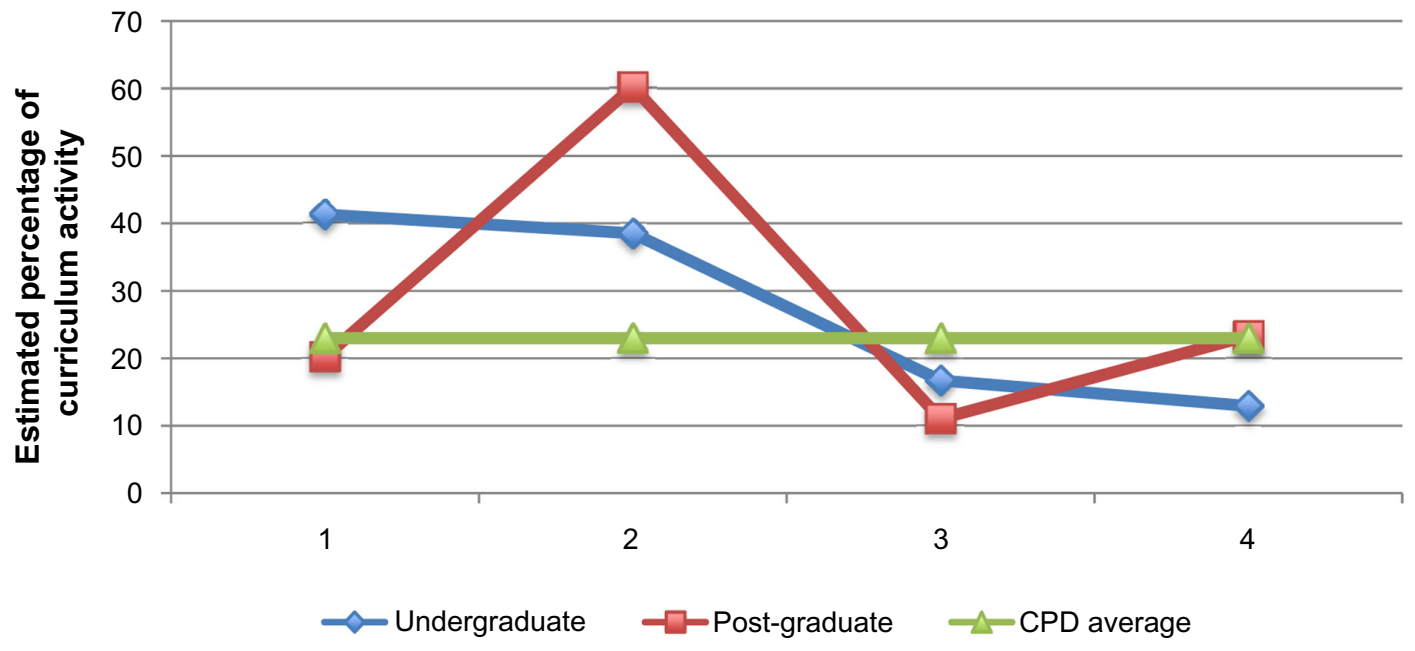

Figure 2 Estimated use of simulation activities through educational years. Abbreviation: CPD, continuing professional development. 
Table 3 Simulation use as it pertains to core competencies of practice

\begin{tabular}{llll}
\hline Competency/domain & $\begin{array}{l}\text { Percent respondents } \\
\text { reporting use of } \\
\text { simulation }\end{array}$ & $\begin{array}{l}\text { Percent respondents } \\
\text { indicating simulation } \\
\text { is part of the curriculum }\end{array}$ & $\begin{array}{l}\text { Estimated share } \\
\text { (\%) of simulation } \\
\text { in the curriculum }\end{array}$ \\
\hline Skill acquisition/competency & 80 & 58 & 37 \\
Patient safety & 78 & 63 & 20 \\
Communication & 70 & 63 & 24 \\
Collaboration/interprofessional & 70 & 58 & 22 \\
team training & & & 19 \\
Manager/resource management & 35 & 33 & 8 \\
Scholarly activities & 45 & 40 & 17 \\
Professionalism & 45 & 40 & 7 \\
Health advocacy & 23 & 20 & \\
\hline
\end{tabular}

simulation centers around the world. Through site visits, the importance of leadership support and cultural readiness for change emerged as important change agents for the future, while protecting traditional education practices and resistance to change in education were identified as major barriers to success.

\section{Future directions}

Most simulation centers $(27 / 42)$ were positive on the future of simulation, predicting a 55\% growth in the next 5 years in terms of funding allocated to simulation programs. The majority of centers believe that the following factors will influence the development of simulation programs:

- Needs of learners - learners are the driving force for simulation-based education, so as numbers of learners increases, so should the size of the facilities.

- Vision of educators - as the model of health care education changes, educators must adapt from individualized education to team-based training; simulation can allow interprofessional groups to learn in team settings.

- Global collaboration - basic questions around simulationbased education cannot be answered without strong collaborations amongst simulation centers for increased funding support, faculty training, generating guidelines, and changing policies.

- Sustainable funding - the allocation of sustainable funds for education and research, and the redistribution of existing funds for simulation activities were identified as major factors contributing to future growth of the international simulation community.

\section{Discussion}

Our results show that global growth of simulation is sporadic and unequal, with enormous discrepancies with respect to learner groups, curricular integration, use of simulators, research activities, infrastructure support, and perceived

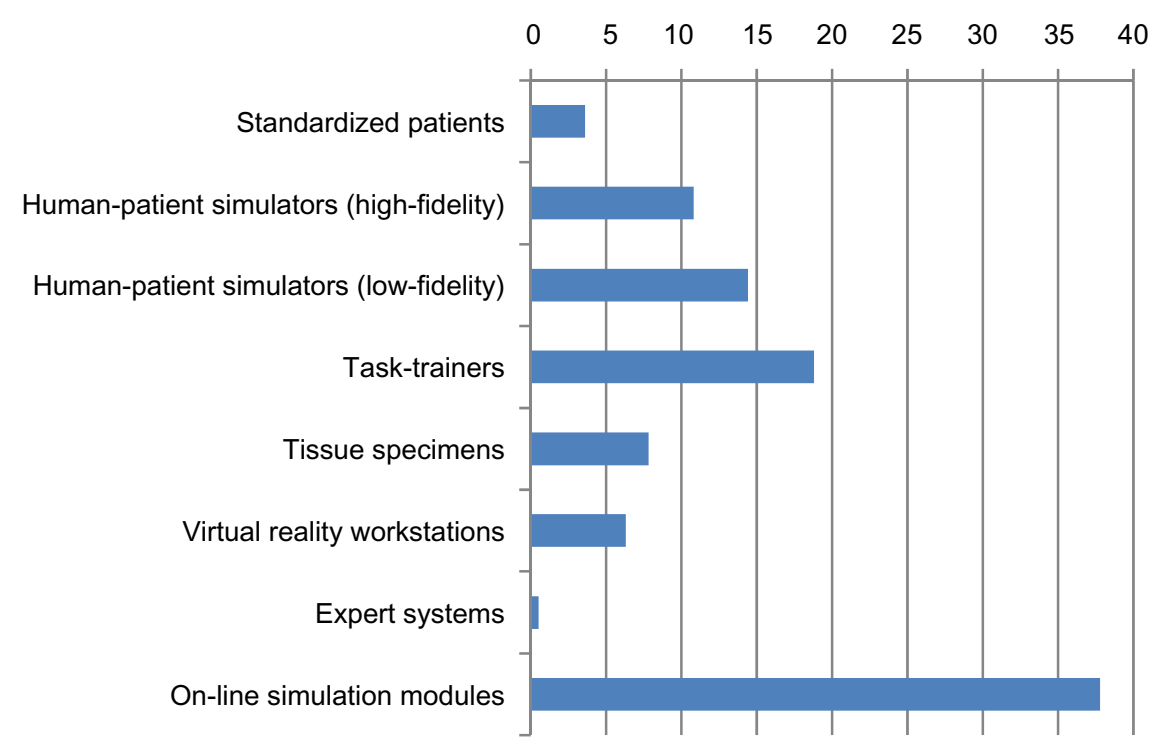

Figure 3 Average Activity Index values for different simulation types. 
Table 4 Strengths and barriers to simulation indicated by centers surveyed

\begin{tabular}{ll}
\hline Strengths \\
35 & Dedicated financial support for operating budget \\
27 & Dedicated simulation technician \\
22 & Support from institutional leaders \\
20 & Curriculum development and implementation \\
18 & Instructor training \\
16 & Dedicated simulation nurse/RT educator with protected time \\
16 & Research program \\
15 & Collaboration with other leading centers \\
15 & Dedicated medical director with protected time \\
15 & Engaging health care workers in improving patient safety \\
14 & Simulation operator training \\
9 & Dedicated simulation administrator/coordinator \\
Barriers & \\
29 & Increased financial support \\
23 & Dedicated simulation technician \\
17 & Increased collaboration with other leading centers \\
17 & Dedicated medical director with protected time \\
15 & Instructor training \\
13 & New scenario development \\
11 & Research training \\
10 & Integration of simulation into existing curriculum \\
8 & Increased support from institutional leaders \\
9 & Lack of outcome measurement \\
8 & Simulation operator training \\
6 & Dedicated simulation nurse/RT educator with protected time \\
9 & Dedicated simulation administrator/coordinator \\
\hline
\end{tabular}

Notes: The numbers listed are the number of simulation centres who responded out of 42 . In strengths they responded that they have the item listed, in barriers they responded that each item was a barrier to their furthered success.

Abbreviation: RT, respiratory technician.

strengths and barriers amongst simulation centers. In this discussion, we explore the key areas identified in the survey, and describe how these inform the future of simulation in health care.

\section{Learner groups and curricular integration}

Amongst the groups of learners investigated, simulation is most used in postgraduate medical education, followed by nursing (undergraduate and continuing professional development combined). Interprofessional activities were less frequent, despite the fact that team training was identified as one of the highest priorities in the future of simulation, in this study and others. ${ }^{30-33}$ As such, it is evident that real team training opportunities are often very limited. This may be related to several issues, including but not limited not: limited resources and funding for bringing different professions together; lack of institutional culture promoting interprofessional training; and logistical/scheduling challenges related to gathering individuals from varying professions. Simulation leaders and educators can advocate for interprofessional simulation training by highlighting how simulation-based education provides unique opportunities for hands-on, team-based training, with the potential for both an immediate and long-term impact on improved patient safety outcomes. ${ }^{28}$

Integration of simulation into curricular activities was highly variable, not only amongst institutions but also within learner groups at each institution. The integration of simulation into undergraduate (nursing and/or medical schools) and postgraduate education is higher in the first 2 years of the programs, decreasing over the last 2 years. This pattern of reduced integration during the clinical years of undergraduate training is particularly worrisome, as it suggests that educators are not fully integrating simulation as learners progress through training. The same could be said for postgraduate learners, where opportunities for immersive clinical experiences of increasing difficulty and complexity are critically important as trainees advance.

To optimize the educational impact of simulation in health care, simulation should be thoughtfully integrated into undergraduate and postgraduate programs (at all levels) throughout training. Doing so requires consideration of: aligning the simulation teaching modality to curricular goals and objectives; ensuring adequate resources (staffing, equipment); and building support from educational leadership.

Although many simulation centers report the use of simulation to enhance patient safety, few of these programs specifically designed a curriculum tailored to patient safety. To fully integrate patient safety into the curriculum, simulation programs should work closely with risk management, patient safety committees, and hospital administrations to pointedly address patient safety issues. As described by others, ${ }^{14}$ the following can be taken into consideration when patient safety issues are addressed by use of simulation:

- Addressing the mundane, as simulation can be used to evaluate common events and probe the readiness of health care systems for potential errors and improvements.

- Evaluating current clinical projects for applications of simulation, rather than vice versa.

- Seeking applications for simulation with immediate outcomes in daily patient care such as the evaluation and purchasing of new bedside equipment.

These strategies will help to improve patient outcomes from simulation-based education. Furthermore, our data suggest that simulation is used little for some CanMEDS competencies, such as professionalism, management, and health advocacy. These gaps suggest a need for simulation educators to identify innovative ways to integrate these key competencies into future simulation curriculum. 


\section{Use of different categories of simulators}

On-line simulation modules and task trainers were most used, with standardized patients and virtual reality used the least. Online simulation modules offer interactive interfaces, delivering knowledge to a potentially large learner population asynchronously, while being relatively low cost (ie, no in-person faculty required). Meanwhile, task trainers (varying levels of fidelity) afford learners the opportunity to practice and master essential procedural skills before performing these in clinical environments. The categories of least-used simulators are highly resource-intensive with the added need for trained facilitators, actors, and/or information technology support. These additional requirements may make it difficult for programs to implement and integrate these types of simulation at an institutional level. Programs should aim to identify situations where more resource-intensive forms of simulation are optimally used to enhance learner performance and patient care.

\section{Research and academic productivity}

Although our study identified a growing community of active simulation-based researchers around the world, we also noted that the bulk of academic productivity was attributed to only a small handful of academic simulation programs. As such, the growth of simulation-based research on a global level will be dependent upon effective collaboration, sharing and expanding research expertise, and identifying a common research agenda to advance the field.

Existing societies, such as the Society for Simulation in Healthcare, are helping to advance simulation research by hosting simulation research summits and publishing consensus papers. ${ }^{34,35}$ The establishment of international research networks, ${ }^{36}$ such as the International Network for Simulation-based Pediatric Innovation, Research and Education, have gathered together like-minded researchers from around the globe to conducting highly impactful, multicenter, simulation-based research studies that will help inform the future of simulation-based education. ${ }^{37}$ These sorts of initiatives and collaborations will be essential to ensuring consistent growth of simulation-based research in programs around the world.

\section{Infrastructure support, strengths, and barriers}

Among the list of barriers described in our results, three stood out as most hindering the advancement of simulation in health care education: a lack of sustainable financial support or business model, a lack of dedicated simulation specialists/ technicians, and a lack of collaborative activities with leading centers internationally. These barriers have been identified by other groups in previous publications. ${ }^{11,16}$ By contrast, centers with fee-for-service business models or centers with stable financial support from their organizations and institutional leaders tend to have several simulation specialists and demonstrated confidence in their ability to expand programs and maintain future sustainability. Our data also indicate discrepancies between centers in terms of financial support and recruitment of qualified professionals, particularly in the area of simulation-based research. Centers stated that in the absence of suitable infrastructure, tools, and environments for clinical outcome studies, they were less able to conduct meaningful assessments on the value of simulation in health care education.

Simulation is an expensive proposition and requires space, equipment, manpower, and other elements, with the costs of simulation activities often underestimated and under investigated. ${ }^{31}$ The true value proposition of simulation in relation to other methods of teaching is yet to be established, and therefore it is often difficult for institutions to fully support themselves and provide a full spectrum of simulation-based education and research opportunities. In order to fully integrate simulation into educational curricula, simulation must be formally included in the budget of health care institutions, while concurrently exploring opportunities for collaboration amongst regional centers. To achieve this goal, simulation centers should consider the following approaches to funding simulation:

- Allocation of new funds by provincial/state and federal governments, health care and educational institutions, granting agencies, and others. Governments of the USA, Australia, Israel, and Saudi Arabia have adopted high levels of support for simulation in health care education.

- Redistribution of existing funds (eg, tuition fees). The reallocation of funds is dependent upon simulation covering learning objectives in a more effective and interactive manner than other modes of education.

- Financial incentives from health insurance companies. Reimbursement to health organizations for delivery of simulation-based education has been implemented some parts of the USA.

- Improved patient safety. A major incentive for simulation in health education is improving patient safety by reduction of errors and improving patient outcomes. With funds saved from improved patient safety, health care institutions can recover costs and reduce expenditures. ${ }^{38}$ 


\section{Future directions}

In our study, we found that simulation experts predicted a $55 \%$ growth in the next 5 years in terms of funding allocated to simulation programs. This is in contrast with the British Columbia Simulation Task Force Paper, ${ }^{28}$ where simulation experts projected $10 \%-20 \%$ growth in simulation in health care education. This pessimistic vision is probably owed to frustrations surrounding the limited financing and administrative support for simulation centers. In fact, the majority of elite specialists and pedagogues in the field believe that in the next 5 years simulation must grow at least $100 \%$ to reach the level of simulation programs in fields such as aviation, military, law enforcement, and the judiciary system. ${ }^{1-5}$ This highlights the importance of the four factors identified by the experts surveyed in our study, ie, needs of learners, vision of educators, global collaboration, and sustainable funding, in shaping the future direction and growth of simulation on a global scale.

\section{Limitations}

Our study had several limitations. The largest number of sites that participated in our study was from North America, and many were accredited simulation programs, so our results may be subject to selection bias. The survey portion of the study was completed nearly 2 years ago, so the results reflect the state of simulation at that time. There has been substantial growth of the simulation community since then, so the global status of simulation in health care education at the present moment is likely to be different. Lastly, we assumed that the responses provided in the survey were an accurate reflection of the program activities as we did not formally capture quantitative data during our site visits.

\section{Summary}

The results of this study indicate that simulation in health care education suffers from a lack of substantial financial support. As a result, curricular integration, use of simulation technology, research productivity, and infrastructure support are substandard in many simulation centers. These struggles prevent simulation in health care from effectively expanding its horizons to other important areas, such as faculty development, patient safety, professionalism, and advocacy. Sustainable growth for simulation on a global scale will require a coordinated and collaborative effort from leading simulation centers and experts around the world.

\section{Recommendations}

\section{Learner groups and curricular integration}

We recommend that educational and health care authorities, as well as accreditation and licensing bodies, support the integration of simulation into health care education for all learner groups. This can be achieved by:

- Recognizing simulation-based education as a central modality in the maintenance of competencies in health care

- Setting standards on the expected proficiencies of health care professionals, and identifying how simulation can assist in achieving and maintaining those standards

- Designing and delivering simulation curriculum for patient safety, professionalism and advocacy-related competencies

- Encouraging collaboration between and within institutions to promote sharing of existing and new curriculum and expertise.

\section{Use of different categories of simulators}

Given the breadth of available simulators and cost considerations for each, we recommend that simulation programs carefully select the ideal simulation modality based on learning needs/objectives, learner group type, number of learners, and cost-effectiveness of the selected learning modality.

\section{Research and academic productivity}

To promote the growth of simulation-based research on a global scale, we recommend the development of improved opportunities for collaboration and networking. These opportunities will enhance expertise, expand potential for multicenter simulation studies, and further the quality of future simulation-based research.

\section{Infrastructure support}

We recommend improved financial support for simulation in health care education. This can be achieved by a variety of methods described above, including allocation of new and existing funds to simulation, increased financial incentive from insurance companies, and demonstrating cost-savings through enhanced patient safety.

\section{Acknowledgments}

We cordially thank all institutions and organizations for their participation in this study and also for their time, effort, and hospitality during the site visits. We would like to especially thank Dr Peter Brooks for providing the opportunity for us to visit most centers in Australia. We are also 
grateful to Dr Gavin Stuart, Dean, Faculty of Medicine at the University of British Columbia, and Dr Garth Warnock, Head, Department of Surgery, University of British Columbia, for approving Dr Karim Qayumi's sabbatical to complete this work. We also acknowledge the Royal College of Physicians and Surgeons of Canada and the American College of Surgeons for providing the opportunity for discussion forums. Funding for travel to all national and international simulation centers was provided in part by the Royal College of Physicians and Surgeons of Canada and in part by the Canadian Patient Safety Institute.

\section{Disclosure}

The authors report no conflicts of interest in this work.

\section{References}

1. Salas E, Bowers CA, Rhodenizer L. It is not how much you have but how you use it: toward a rational use of simulation to support aviation training. Int J Aviat Psychol. 1998;8:197-208.

2. Allerton DJ. The case for flight simulation in general aviation. Keynote address at the Royal Aeronautical Society Conference on Aircrew Training, May 16, 2001, London, UK.

3. Macedonia M. Games, simulation, and the military education dilemma. Available from: https://net.educause.edu/ir/library/pdf/ffpiu018.pdf. Accessed August 8, 2014.

4. Bennell C, Jones NJ, Corey S. Does use-of-force simulation training in Canadian police agencies incorporate principles of effective training? Psychology, Public Policy, and Law. 2007;13:35-58.

5. Simon SM, Landsman MS. Judicial ethics simulation based training. Law Contemp Probl. 1995;58:323-336.

6. UF Simulation in Health Care. Technology development. Available from: http://simulation.health.ufl.edu/research/index.php. Accessed August 15, 2013.

7. Rosen KR. The history of medical simulation. J Crit Care. 2008;23: 157-166.

8. Bhishangratna KK, editor. The Sushruta Samhita: An English Translation Volume II. 1911.

9. Qayumi K. Centers of excellence: a new dimension in surgical education. Surg Innov. 2006;13:120-128.

10. Sachdeva AK, Pellegrini CA, Johnson KA. Support for simulation-based surgical education through American College of Surgeons - accredited education institutes. World J Surg. 2008;32:196-207.

11. Ziv A, Wolpe PR, Small SD, Glick S. Simulation-based medical education: an ethical imperative. Acad Med. 2003;78:783-788.

12. Aggarwal R, Mytton OT, Derbrew M, et al. Training and simulation for patient safety. Qual Saf Health Care. 2010;19 Suppl 2:i34-i43.

13. Gaba DM. The future vision of simulation in health care. Qual Saf Health Care. 2004;13 Suppl 1:i2-i10.

14. Zendejas B, Brydges R, Wang AT, Cook DA. Patient outcomes in simulation-based medical education: a systematic review. J Gen Intern Med. 2013;28:1078-1089.

15. Shavit I, Keidan I, Hoffmann Y, et al. Enhancing patient safety during pediatric sedation, the impact of simulation-based training of nonanesthesiologists. Arch Pediatr Adolesc Med. 2007;161:740-743.

16. Schmidt E, Goldhaber-Fiebert SN, Ho LA, McDonald KM. Simulation exercises as a patient safety strategy. Ann Intern Med. 2013;158(5 Pt 2): 426-432.

17. Issenberg SB, Chung HS, Devine LA. Patient safety training simulations based on competency criteria of the Accreditation Council for Graduate Medical Education. Mt Sinai J Med. 2011;78:842-853.
18. Huang L, Norman D, Chen R. Addressing hospital wide patient safety initiatives with high-fidelity simulation. Physician Exec. 2010;36:34-39.

19. Salas E, Wilson KA, Burke CS, Priest HA. Using simulation-based training to improve patient safety: what does it take? Jt Comm J Qual Patient Saf. 2005;31:363-371.

20. CAE Healthcare. Available from: http://www.caehealthcare.com. Accessed August 15, 2013.

21. Oregon Simulation Alliance. About OSA, Vision, Mission and History. 2010. Available from: http://www.oregonsimulation.com/about/visionmission-and-history/. Accessed November 15, 2010.

22. Ziv A, Erez D, Munz Y, et al. The Israel Center for Medical Simulation: a paradigm for cultural change in medical education. Acad Med. 2006;81:1091-1097.

23. Uniformed Services University of the Health Sciences. The National Capital Area Medical Simulation Center, Vision, Mission and History. 2010. Available from: http://simcen.usuhs.edu/aboutus/Pages/default. aspx. Accessed November 15, 2010.

24. Cormack M. Developing a national approach to clinical education: embedding a distributed simulation program. Presented at the Medical Simulation Symposium, August 30 to September 2, 2010, Adelaide, Australia.

25. Felländer-Tsai L, Westfelt P, Escher C, Hedsköld M, Kjellin A. The Center for Advanced Medical Simulation, Karolinska Institutet, Karolinska University Hospital, and Stockholm County Council. J Surg Educ. 2010;67:344-347.

26. Okuda Y, Bryson EO, DeMaria S Jr, et al. The utility of simulation in medical education: what is the evidence? Mt Sinai J Med. 2009;76(4): 330-343.

27. Soper NJ, Fried GM. The fundamentals of laparoscopic surgery: its time has come. Bull Am Coll Surg. 2008;93:30-32.

28. Qayumi K, Donn S, Zheng B, et al. British Columbia interprofessional model for simulation-based education in health care. A network of simulation sites. Simul Healthc. 2012;7(5):295-307.

29. Frank JR, Jabbour M. Report of the CanMEDS Phase IV Working Groups. Ottawa, ON, Canada: Royal College of Physicians and Surgeons of Canada; 2005.

30. Michelson JD, Manning L. Competency assessment in simulation-based procedural education. Am J Surg. 2008;196:609-615.

31. Scalese RJ, Obeso VT, Issenberg SB. Simulation technology for skills training and competency assessment in medical education. J Gen Intern Med. 2008;23 Suppl 1:46-49.

32. Rosen MA, Salas E, Wilson KA, et al. Measuring team-performance in simulation-based training: adopting best practices for health care. Simul Healthc. 2008;3:33-41.

33. Shapiro MJ, Morey JC, Small SD, et al. Simulation based teamwork training for emergency department staff: does it improve clinical team performance when added to an existing didactic teamwork curriculum? Qual Saf Health Care. 2004;13:417-421.

34. Issenberg SB, Ringsted C, Ostergaard D, Dieckmann P. Setting a research agenda for simulation-based health care education. A synthesis of the outcome from a Utstein style meeting. Simul Healthc. 2011;6: 155-167.

35. Raemer D, Anderson M, Cheng A, Fanning R, Nadkarni V, Savoldelli G. Research regarding debriefing as part of the learning process. Simul Healthc. 2011;6 Suppl:S52-S57.

36. Cheng A, Hunt EA, Donoghue A, et al; EXPRESS Pediatric Simulation Research Investigators. EXPRESS - examining pediatric resuscitation education using simulation and scripting: the birth of an international pediatric simulation research collaborative - from concept to reality. Simul Healthc. 2011;6:34-41.

37. Cheng A, Auerbach M, Hunt EA, et al. Designing and conducting simulation-based research. Pediatrics. 2014;133:1091-1101.

38. Huang L, Norman D, Chen R. Addressing hospital-wide patient safety initiatives with high-fidelity simulation. Physician Exec. 2010;36: 34-39. 
Advances in Medical Education and Practice

Dovepress

\section{Publish your work in this journal}

Advances in Medical Education and Practice is an international, peerreviewed, open access journal that aims to present and publish research on Medical Education covering medical, dental, nursing and allied health care professional education. The journal covers undergraduate education, postgraduate training and continuing medical education including emerging trends and innovative models linking education, research, and health care services. The manuscript management system is completely online and includes a very quick and fair peer-review system. Visit http://www.dovepress.com/testimonials.php to read real quotes from published authors.

Submit your manuscript here: http://www.dovepress.com/advances-in-medical-education-and-practice-journal 